\title{
The National Interest Waiver Program: Obtaining a Green Card without a Labor Certification
}

\section{David Nachman, Michael Phulwani, and Ridhima Goyal}

In instances where the interest of the United States is being served, non-U.S. citizens who want to live and work in the United States can seek a National Interest Waiver to obtain a green card. (A green card holder is someone who has been granted authorization to live and work in the United States on a permanent basis.) The National Interest Waiver classification is a waiver of the Labor Certification Application (PERM) requirement, which is a costly and time-consuming way to obtain a green card. The PERM process requires a U.S. employer to apply to the U.S. Department of Labor for a certification to demonstrate that there are no able, willing, and qualified U.S. workers who can take the job.

On the other hand, the National Interest Waiver classification is an Employment-Based Immigration Second Preference (EB-2) category. The National Interest Waiver does not require an employer to sponsor the application. What distinguishes an EB-2 from an EB-2 with a National Interest Waiver is that the latter does not require proof of a job offer but rather the potential for a future job. However, if a National Interest Waiver Application is sponsored by an employer, the case tends to be stronger.

The National Interest Waiver application may be of particular interest to professionals seeking to immigrate to the United States because an employer sponsorship is not necessary. However, applicants should have significant potential for research and for obtaining grants and government funding for exploring original sci- entific contributions to an academic field.

According the United States Citizenship and Immigration Services (USCIS), the jobs that may qualify for a National Interest Waiver are not defined by statute or by the regulations. Rather, National Interest Waivers are usually granted to those who have "exceptional ability" in their field of work and whose employment in the United States would greatly benefit national interests. Those seeking a National Interest Waiver may self-petition, filing the Labor Certification directly with the USCIS along with their Form I-140, Petition for Alien Worker.

Evidence that can and should be included in the National Interest Waiver includes (but is not limited to):

- An official academic record showing that the applicant has a degree, diploma, certificate, or similar award from a college, university, school, or other institution of learning related to an area of exceptional ability

- Letters documenting at least ten years of full-time experience in one's occupation

- A license to practice one's profession or certification for one's profession or occupation

- Evidence that the applicant has commanded a salary or other remuneration for services that demonstrates exceptional ability

- Membership in a professional association

- Recognition for achievements and significant contributions in the applicant's industry or field by peers, government entities, professional or business organizations

- Any other comparable evidence of eligibility

Thus, highly skilled professionals in areas such as the arts, sciences, or business who can prove they have "exceptional abilities" and that their presence in the United States has the potential to significantly benefit U.S. economic, cultural, or educational interests may be qualified to apply for the EB-2 National Interest Waiver visa classification.

The USCIS will judge if the case has "substantial intrinsic merit" and how the applicant's skills and abilities and work will benefit the United States as a whole. What essentially this means is that one must not only meet the criteria for an EB-2 (listed above) but that the applicant and his/her intended work in the United States must display incomparable appeal. Not every case is worthy of consideration for submission as a National Interest Waiver. However, for those individuals who possess very impressive academic and experiential backgrounds, and who are doing work that (it may be argued) is or will benefit the United States as a whole, there may be a good route to get to the green card in a shorter time then it may take in the Employment-based Third Preference Category (which may take many years).

David Nachman, Michael Phulwani, and Ridhima Goyal are with the Nachman Phulwani Zimovcak (NPZ) Law Group, P.C., Visaserve Plaza, 487 Goffle Road, Ridgewood, New Jersey 07450. Phone (201) 670-0006 (x100); e-mail info@visaserve.com. 